\title{
Qué pensar antes de decir que el paciente tiene un diagnóstico psiquiátrico.
}

\section{Parte I}

\begin{abstract}
Héctor Jairo Umaña Giraldo ${ }^{1}$, Daniel S. Marín-Medina ${ }^{1}$ cercavlejos@utp.edu.co ,Daniel Ricardo Arias-Jaramillo ${ }^{1}$ Jessica Andrea López-Posada $^{1}$, Eliana Lucía Rodríguez-Suárez ${ }^{1}$, Manuela Gámez-Cárdenas ${ }^{1}$, Tatiana Álvarez-Vera ${ }^{1}$
\end{abstract}

${ }^{1}$ Universidad Tecnológica de Pereira, Facultad de Ciencias de la Salud. Risaralda, Colombia.

\begin{abstract}
Resumen
Los pacientes refieren sus síntomas en una gran variedad de términos como: "estoy cansado", "me duelen las articulaciones", "me pica todo el cuerpo", "tengo la boca seca", entre otros. Ante estos síntomas el médico piensa de manera automática en un número limitado de patologías que le son familiares, pero existen muchas otras causas a estos síntomas que no se tienen en cuenta. El desconocimiento del médico hace que en el paciente se genere inconformidad al no tenerse un diagnóstico correcto y un tratamiento adecuado, esto lleva a múltiples consultas y que el médico llegue a preguntarse a sí mismo "¿será que este paciente tiene un diagnóstico psiquiátrico?". En este artículo se enumeran las causas frecuentes de estos síntomas mencionados, se describen causas que son pocas veces sospechadas y las claves clínicas para que el médico pueda hacer el diagnóstico de éstas. La primera parte desarrollará los síntomas: fatiga, parestesias, prurito, artralgias, ansiedad y cambios en el comportamiento. La segunda parte desarrollará los síntomas: intolerancia a los alimentos, xerostomía, síncope, disfagia y manifestaciones en pacientes con cirugía bariátrica.
\end{abstract}

Palabras claves: diagnóstico; fatiga; artralgia; parestesias; prurito; ansiedad.

Copyright (C) Facultad de Ciencias de la Salud de la Universidad Tecnológica de Pereira. 1995-2018. Todos los derechos reservados
What do you think before that you said: the patient has a psychiatric diagnosis. Part I

\begin{abstract}
Patients refer their symptoms in a variety of terms such as: "I am tired", "my joints hurt", "my body itches", "my mouth is dry", among others. Given these symptoms, the doctor automatically thinks in a limited number of pathologies that are familiar to him, but there are many other causes to these symptoms that are not taken into account. The lack of knowledge of the doctor causes the patient to be dissatisfied by not having a correct diagnosis and adequate treatment, this leads to multiple visits and the doctor comes to ask himself "will this patient have a psychiatric diagnosis?". This article lists the frequent causes of these symptoms, describes causes that are rarely suspected and the clinical keys for the doctor to diagnose them. The first part will address the symptoms: fatigue, paresthesia, pruritus, arthralgia, anxiety and changes in behavior. The second part will develop the symptoms: intolerance to food, xerostomia, syncope, dysphagia and manifestations in patients with bariatric surgery.
\end{abstract}

Key words: diagnosis; fatigue; arthralgia; paresthesia; pruritus; anxiety.

Copyright (C) Facultad de Ciencias de la Salud de la Universidad Tecnológica de Pereira. 1995-2018. Todos los derechos reservados

\section{Introducción}

Muchas veces el médico se encuentra con síntomas referidos por sus pacientes que le son de difícil interpretación. La pregunta: “iserá que este paciente tiene un diagnóstico psiquiátrico?" se formula en la mente del médico cuando reflexiona sobre los síntomas del paciente.

Son varios los síntomas que causan incertidumbre al no hallar una posibilidad diagnóstica dentro del marco común de enfermedades conocidas por el médico, algunos son referidos por el paciente como: "estoy cansado", "todo me cae mal", "siento picotazos o ardores" y "tengo la boca seca". Estos síntomas frecuentes en la consulta causan malestar en el médico y el paciente por la poca mejoría con los tratamientos debido a la dificultad en el diagnóstico.

En este artículo de revisión se busca informar al médico de otras opciones diagnósticas que no son consideradas de forma rutinaria en la consulta.

\section{El paciente que refiere: "Me siento cansado"}

La fatiga es la dificultad para iniciar o mantener la actividad física o mental de manera voluntaria. Esta llama la atención cuando no tiene una causa evidente o cuando su gravedad es mucho mayor a la esperada. En la población general, puede alcanzar prevalencias tan altas como del $18-23 \%$ [1]. En la fatiga, a diferencia de la debilidad muscular, no hay compromiso de la fuerza en el examen neurológico. También debe diferenciarse de la somnolencia y la disnea de esfuerzo que pueden ser referidas de la misma forma por el paciente. 
Causas de fatiga son:

- Enfermedad de Parkinson, esclerosis lateral amiotrófica y secuelas de enfermedad cerebrovascular (ECV).

- Hipo e hipertiroidismo, hiperglucemia y enfermedad de Cushing.

- Insuficiencia hepática crónica e insuficiencia renal crónica.

- Obesidad con o sin apnea obstructiva del sueño.

- VIH, hepatitis crónica B y C.

- Antidepresivos, antipsicóticos, ansiolíticos, opioides, antiepilépticos y beta-bloqueadores.

- Consumo crónico de alcohol.

- Insuficiencia cardíaca congestiva (ICC), hipertensión pulmonar (HTP)

y enfermedad pulmonar obstructiva crónica (EPOC).

- Anemia y malignidad.

- Polimialgia reumática, artritis reumatoide (AR), lupus eritematoso

sistémico (LES) y enfermedad intestinal inflamatoria.

- Embarazo y puerperio.

- Fibromialgia y síndrome de fatiga crónica.

Otras causas a considerar son:

\section{Hipogonadismo}

El 38\% de los hombres mayores de 45 años presentan hipogonadismo [2]. Los niveles bajos de testosterona, incluso en menores de 40 años, se asocian a disminución del ánimo, falta de energía, debilidad y deterioro en el trabajo [3]. La fatiga está presente en el $40 \%$ de los casos [4]. Otros síntomas son irritabilidad, disminución en la atención y la libido, disfunción eréctil matutina, anorgasmia, menor sensibilidad en el pene, pérdida de masa muscular, aumento de grasa corporal y ginecomastia [5].

\section{Fatiga por lesión traumática cerebral}

La hormona de crecimiento es la más vulnerable a la injuria traumática cerebral y su deficiencia se produce en el $20 \%$ de los pacientes con trauma craneoencefálico [6]. La fatiga aparece incluso luego de lesiones cerebrales leves, es severa los primeros días y persiste por meses [7]. Es frecuente el compromiso de la memoria y atención, irritabilidad, depresión, ansiedad y trastornos del sueño [8-10].

\section{Miastenia gravis}

La prevalencia está entre 1,5 y 17,9 casos por 100000 habitantes [11]. Hasta el $82 \%$ de los pacientes tienen fatiga, esta empeora a lo largo del día, con las actividades repetitivas y mejora con el descanso $[12,13]$. La diplopía es la forma de inicio en el $50 \%$ de los pacientes [14]. Otros síntomas son disfagia o fatiga al masticar, voz nasal, ptosis palpebral, debilidad muscular proximal, pérdida de la sonrisa y cabeza caída [15]. Los reflejos osteotendinosos son normales y nunca se compromete la pupila [16].

\section{Síndrome de Lambert-Eaton}

Tiene una prevalencia de 3,4 casos por millón. La fatiga se presenta desde la mañana y tiende a mejorar a lo largo del día. A diferencia de la miastenia gravis, cursa con arreflexia y tanto la debilidad como la arreflexia mejoran con el movimiento repetido [17]. La sensación de boca seca y disfunción eréctil pueden ser la manifestación inicial en el
45 a $77 \%$ de los casos [18]. El compromiso ocular es tardío y leve [19]. Se asocia a cáncer de pulmón, mama, próstata, recto y linfoma [20].

\section{Esclerosis múltiple}

En Colombia hay 7,52 casos por cada 100000 habitantes [21]. El $75 \%$ de los pacientes presenta fatiga que aparece con los ataques agudos, puede preceder los otros síntomas neurológicos y persistir luego del episodio [22, 23]. Las formas más frecuentes de presentación son pérdida sensitiva, neuritis óptica, debilidad, fatiga, parestesias, diplopía y ataxia [24]. Otras características son dolor, depresión, compromiso cognitivo, pérdida de la visión, oftalmoplejia internuclear, nistagmus, vértigo, alteración de la marcha, signo de Lhermitte, vértigo, disfunción vesical y sexual [25]. El 60 a $80 \%$ de los pacientes presenta empeoramiento de los síntomas con el calor [26].

\section{Síndrome de Sjögren}

La forma primaria tiene una prevalencia del 2,7\% [27]. Afecta pacientes entre los 40 y 50 años de edad. Hasta el $80 \%$ de los pacientes tiene la triada de boca-ojo seco, fatiga y dolor articular [28]. El 70\% tienen fatiga que puede ser incapacitante [29]. Los pacientes refieren fatiga después de levantarse en la mañana, luego mejora hacia el mediodía y vuelve a empeorar en la noche, a diferencia del LES en el que se levantan en la mañana sin fatiga [30].

\section{Apnea obstructiva del sueño sin obesidad}

El $20 \%$ de los pacientes con apnea obstructiva del sueño no son obesos y tienen cuatro veces más riesgo de hipertensión que los pacientes con obesidad [31-33]. Estos pacientes consumen alcohol o tabaco, son sedentarios y duermen en posición decúbito supino [34]. La fatiga empieza en la mañana y persiste durante el día. Se debe sospechar cuando hay ronquido habitual reportado por un familiar o la pareja y somnolencia diurna excesiva. Otros síntomas son sueño intranquilo, diaforesis, impotencia sexual, disminución de la libido, nocturia y enuresis [35].

\section{Cirrosis biliar primaria}

La prevalencia es de 150 a 400 casos por millón [36]. El 78\% de los pacientes presentan fatiga y 20 a $70 \%$ prurito [37]. La fatiga es incapacitante, no mejora a lo largo del día y genera alteraciones del ánimo [38]. Se asocia a hiperlipidemia, hipotiroidismo, síndrome de Sjögren y esclerodermia [37]. El 50\% tienen hiperpigmentación [39].

\section{Enfermedad de Addison}

Se sospecha en un paciente con hipotensión arterial postural, signo que aparece en todos los casos [40]. Otros síntomas son poliuria, náusea, vómito, pérdida de peso, fiebre, dolor abdominal, hiperpigmentación, hiponatremia, hiperpotasemia e hipoglucemia $[40,41]$. La fatiga está presente de manera crónica y puede ser indistinguible de la fibromialgia y el síndrome de fatiga crónica [42, 43].

\section{Enfermedades infecciosas}

Fiebre Q crónica: El 23\% de la población rural colombiana tiene anticuerpos contra Coxiella burnetti [44]. No es necesaria la exposición directa a la espora porque el agente infeccioso puede estar tan distante como a $18 \mathrm{~km}$ [45]. Seis a doce meses después de la presentación aguda de la enfermedad aparece fatiga, diaforesis nocturna, mialgias, artralgias, dificultad en la memoria y atención, cambios de ánimo y sueño no reparador [46-48].

Mononucleosis infecciosa: Del 9 a $12 \%$ de los pacientes pueden tener fatiga hasta seis meses o más después del episodio agudo [4950]. 


\section{Abuso sexual y físico}

Es frecuente en mujeres diagnosticadas con síndrome de fatiga crónica y fibromialgia. El abuso sexual y físico en la infancia aumenta seis veces el riesgo de fatiga crónica en el adulto y se asocia a fatiga por condiciones médicas o psiquiátricas $[51,52]$. La fatiga a menudo se acompaña de cefalea y trastornos del sueño. También se asocia a trastornos gastrointestinales, depresión, ansiedad, abuso de alcohol y drogas, dolor crónico y múltiples síntomas somáticos [52, 54].

\section{Trastornos electrolíticos}

Hipercalcemia: El hiperparatiroidismo está presente en 7 de cada 1000 individuos [55]. Es causa frecuente de poliuria, polidipsia, debilidad, dolor abdominal, cólico renal, irritabilidad, ánimo deprimido y QT corto en el electrocardiograma [56].

Hipopotasemia: E1 20\% de los casos de hipertensión arterial resistente son ocasionados por hiperaldosteronismo [57], el cual está asociado a hipopotasemia en el 30\% de los pacientes [58]. El 14\% de la población puede tener hipopotasemia y el $80 \%$ de los que reciben diuréticos la presentan [59]. La debilidad y fatiga aumentan de acuerdo a la severidad de la hipopotasemia. Otros síntomas son parestesias en piernas, estreñimiento y anormalidades en el electrocardiograma (ondas U, aplanamiento de la onda $\mathrm{T}$ y cambios del segmento ST) $[59,60]$.

\section{Baja concentración de ferritina sin anemia}

Puede ser tres veces más común que la anemia ferropénica y afecta al 20\% de las mujeres. Es frecuente el déficit de atención, memoria y aprendizaje. Estos pacientes se benefician de la suplementación con hierro $[61,63]$.

\section{Hipotiroidismo hipofisario}

Los niveles de TSH en el paciente con hipotiroidismo hipofisiario son ligeramente bajos por lo que es indispensable la toma de T4 libre en el paciente con fatiga dado que este puede ser el único síntoma. Otros síntomas son cefalea, somnolencia, piel seca y edema periférico $[64,65]$.

\section{Síndrome de piernas inquietas}

La prevalencia estimada es de 1,9 a $4,6 \%$ [66]. El paciente se queja de sensaciones incómodas profundas en las piernas durante el reposo, en especial al momento de dormir, asociado a urgencia irresistible de mover las extremidades con lo cual obtiene alivio temporal de los síntomas. Otras manifestaciones son fatiga, somnolencia diurna y mioclonias en las piernas. Aparece en pacientes con esclerosis múltiple, en quienes aumenta la fatiga [66-68].

\section{Acidosis tubular renal}

La fatiga es ocasionada por los trastornos electrolíticos concomitantes como hipopotasemia, hipofosfatemia e hipercalciuria. Son causas de acidosis tubular renal: síndrome de Sjögren, medicamentos (topiramato, litio, ibuprofeno, tenofovir y acetazolamida), AR, cirrosis biliar primaria, LES, gammapatías monoclonales, enfermedad de Wilson y hepatitis autoinmune [69-71].

\section{Escorbuto}

La deficiencia de vitamina $\mathrm{C}$ está presente hasta en el $14 \%$ de la población [72]. Esta se manifiesta con fatiga al esfuerzo de lenta progresión y debilidad que responde de manera rápida a la suplementación con vitamina C. Otras manifestaciones son irritabilidad, hipotensión ortostática, anemia, mialgias, dolor óseo, mala curación de heridas, edema gingival con pérdida de dientes, petequias mucocutáneas, formación de hematomas con facilidad, hemorragias perifoliculares, pelos en sacacorcho y sangrado en las encías $[73,74]$.

\section{El paciente ,que refiere: "tengo hormigueos y quemazones"}

Los pacientes pueden referir las parestesias como: sensación de hormigueo, prurito, molestia en forma de banda, sensación de relámpago, punción, opresión, quemadura y entumecimiento [75]

Causas de parestesias son:

- Tumores cerebrales y ECV.

- Neuropatía por atrapamiento, enfermedad de Charcot-MarieTooth, enfermedad de Fabry, polineuritis y trauma.

- Diabetes mellitus, hipotiroidismo y uremia.

- Abuso de alcohol.

- Antirretrovirales.

- Encefalitis y enfermedad de Lyme.

- Fenómeno o enfermedad de Raynaud, LES y AR.

- Compresión o infiltración de nervios por tumores.

Otras causas a considerar son:

\section{Neuropatía de fibra pequeña}

Afecta hasta al 10\% de los mayores de 40 años [76]. Es simétrica, inicia en las extremidades inferiores en forma de calcetín y luego se extiende hacia las extremidades superiores en forma de guante, puede ser dolorosa y compromete las funciones autonómicas. El examen neurológico es casi siempre normal [77]. Puede ser omitida porque no es detectada en la electromiografía convencional [78]. Más de la mitad tienen intolerancia a los carbohidratos u obesidad sin diabetes manifiesta. Otras causas son: VIH, polineuropatía desmielinizante inflamatoria crónica, enfermedad celíaca, hepatitis $\mathrm{C}$, síndrome de piernas inquietas, síndrome de dolor regional complejo, paraproteinemia, LES, síndrome de Sjögren, enfermedad tiroidea, amiloidosis, enfermedad de Fabry y síndromes paraneoplásicos [77].

\section{Deficiencia de vitamina B12}

El déficit está presente en el 20\% de las mujeres adultas en Colombia, aunque en otras poblaciones es mayor [79. 80]. Entre los vegetarianos puede llegar al $85 \%$ [81]. La manifestación más común son las parestesias simétricas y alteraciones en la marcha [82]. Las parestesias inician en las manos (síndrome de la mano entumecida) y pueden ser confundidas con síndrome del túnel carpiano [83, 84]. Hay hipoestesia, hiporreflexia y debilidad simétrica por el compromiso del nervio periférico. En la lesión medular se presenta pérdida de la propiocepción, debilidad de las extremidades, hiperreflexia, signo de Romberg positivo, signo de Lhermitte y niveles sensitivos cutáneos [82, 84]. También puede presentarse compromiso autonómico y neuropatía óptica [82].

\section{Otras deficiencias}

Las deficiencias de vitamina E, piridoxina y cobre se asocian a neuropatía [85]. Estas serán revisadas en la segunda parte.

\section{Espondilosis cervical}

El 22\% de los mayores de 25 años y el 88\% de los mayores de 55 años tienen signos radiológicos, aunque solo el $15 \%$ presentan síntomas [86]. Presenta rigidez, dolor cervical agravado por el movimiento, dolor referido al occipucio, interescapular o extremidades superiores, vértigo o mareos, aumento de la base de sustentación, marcha atáxica, síncope, migraña o dolor torácico. Las parestesias se acompañan de debilidad, hiperestesia o hiperalgesia en las extremidades superiores. El signo de Hoffman y clonus aquiliano son hallazgos comunes [87, 88]. 


\section{Intoxicación por plomo}

El 1\% de la población general tiene niveles elevados de plomo $[89,90]$. La neuropatía tiene predominio motor (muñeca caída y compromiso de músculos extensores de la mano), es asimétrica, más distal que proximal y se acompaña de parestesias $[91,95]$. Otros hallazgos son fatiga, mialgias, cefalea, irritabilidad, deterioro cognitivo, trastornos psiquiátricos, infertilidad, estreñimiento, dolor abdominal, falla renal, hipertensión, anemia microcítica, punteado basófilo y encías azules $[91,95]$.

Otras intoxicaciones que pueden causar parestesias son arsénico, organofosforados, talio, mercurio, cobalto, hexacarbonos, acrilamida, entre otros [85].

\section{Lepra}

En Colombia hay alrededor de 300 a 400 casos cada año (96). El compromiso sensitivo es usualmente la primera manifestación y la neuropatía sin lesiones cutáneas se ve en el 3 a $10 \%$ de los casos. El $79 \%$ de los pacientes presenta mononeuritis, en especial del nervio ulnar. Puede presentarse ulceración y deformidad del pie por compromiso del nervio tibial posterior. En 18\% de los casos se afecta el nervio facial, olfatorio o trigémino. Otros nervios comprometidos son el mediano, auricular posterior, radial superficial, peroneo común y peroneo superficial [97-99].

\section{Vasculitis}

Las vasculitis asociadas a ANCAS, la poliarteritis nodosa y la crioglobulinemia mixta presentan neuropatía hasta en el $70 \%$ de los pacientes [100]. El 30\% de los casos tienen neuropatía sin compromiso sistémico [100]. La caída del pie por compromiso del nervio ciático o peroneo es la manifestación inicial. La principal forma es la mononeuritis múltiple en la que hay pérdida de la sensibilidad, dolor y debilidad asimétrica en varios trayectos nerviosos. La polineuropatía es distal y asimétrica, la radiculopatía o plexopatía se presenta en especial en la poliarteritis nodosa con compromiso sensitivo a lo largo de un dermatoma $[101,103]$.

\section{Síndrome de Sjögren}

E1 5 a $20 \%$ de los pacientes tienen neuropatía [104, 105]. La neuropatía de fibra pequeña es la forma más frecuente. Puede presentarse compromiso asimétrico en la mononeuritis múltiple y compromiso de la vibración, reflejos y propiocepción en la forma sensorial axonal. Otros hallazgos son miopatía inflamatoria, compromiso de pares craneales (trigémino y facial) y alteraciones autonómicas [105-107].

\section{Porfiria}

La prevalencia de las tres principales formas (porfiria cutánea tarda, protoporfiria eritropoyética y porfiria aguda intermitente) es de 1 en 10000 a 1 en 75000 habitantes [108]. De estas, solo la porfiria aguda intermitente tiene manifestaciones neurológicas [109]. Los trastornos sensitivos se desarrollan en el mes siguiente a la presentación de los ataques agudos en el 10 a $40 \%$ de los casos [110]. Las parestesias son asimétricas, predomina el compromiso motor, se afectan pares craneales y puede ir acompañado de trastornos autonómicos, en especial hipertensión arterial, taquicardia y estreñimiento [109-111].

\section{Herpes sin herpes}

El herpes zóster es más común en mayores de 50 años. Es posible que se presente solo con dolor y parestesias a lo largo de un dermatoma, pero sin las lesiones cutáneas. También puede presentarse dolor en dermatomas diferentes al de la zona con las lesiones cutáneas. Debe sospecharse compromiso de pares craneales cuando haya laberintitis, parálisis facial dolorosa, neuralgia oftálmica unilateral o presencia de oftalmoplejía y enfermedad cerebral o espinal de origen desconocido, en especial si se acompaña de pleocitosis en líquido cefalorraquídeo [112-114].

\section{Convulsiones sensitivas focales}

El compromiso del sistema sensitivo se puede manifestar en forma de auras visuales, auditivas, somatosensoriales (parestesias o dolor), propioceptivas, olfatorias y sensitivas. Las auras somatosensitivas ocurren con frecuencia en las crisis focales motoras, en estas aparecen parestesias que al inicio son localizadas, luego comprometen las zonas adyacentes y al final se acompañan de manifestaciones motoras [115-117].

\section{Síndromes paraneoplásicos}

El compromiso sensitivo es simétrico, se acompaña de dolor, parestesias y ataxia sensitiva. También puede presentarse debilidad progresiva, simétrica y distal en la forma sensorimotora. Puede preceder la aparición de tumores como el cáncer de pulmón de células pequeñas, linfoma, páncreas, tiroides, próstata, endometrio, carcinoides del pulmón [118, 119], síndrome de POEMS (polineuropatía, organomegalia, endocrinopatía, gammapatía monoclonal y cambios en la piel) $[120,121]$, mieloma múltiple asociada a amiloidosis [122], enfermedad de Castleman [123, 124] y macroglobulinemia de Waldeström [125, 126]. En ocasiones puede ser indistinguible del síndrome de Guillain-Barré [127]. También puede presentarse mononeuritis múltiple por vasculitis paraneoplásica.

\section{Esclerosis múltiple}

Las parestesias pueden ser la forma de presentación hasta en el $24 \%$ de los casos e inician en las extremidades inferiores [128]. Todos los pacientes presentan parestesias a medida que progresa la enfermedad $[128,129]$.

\section{El paciente "que refiere: "me duelen las}

Las causas de dolor articular con o sin signos inflamatorios son numerosas. El dolor articular sin artritis crea confusión en el médico [130].

Causas de artralgias sin artritis son:

- Infecciones sistémicas o articulares.

- Artropatía por cristales.

- Fracturas.

- Osteoartrosis.

- Síndrome de Sjögren, AR y LES.

- Hepatitis B, parvovirus B19, VIH, HTLV1, rubeola y virus transmitidos por artrópodos

- Artritis reactiva y enfermedad intestinal inflamatoria.

- Enfermedad del suero.

- Fiebre reumática aguda.

- Vasculitis sistémicas primarias.

- Sarcoidosis.

Otras causas a considerar son:

\section{Polimialgia reumática}

Afecta pacientes mayores de 50 años en quienes la incidencia es de 100 casos por 100000 personas al año [131]. Se caracteriza por rigidez matutina mayor a una hora y dolores musculares intensos en cuello y brazos que también pueden ocurrir en la noche. La rigidez mejora a lo largo del día y empeora luego de la inactividad. Todos los paciente tienen dolor en los hombros y el $50 \%$ tienen compromiso 
de la cintura pélvica [132]. Los reactantes de fase aguda pueden ser normales en el $20 \%$ de los pacientes [133]. Está asociada a arteritis de células gigantes en el $30 \%$ de los casos [131].

\section{Lupus eritematoso sistémico}

Tiene una incidencia y prevalencia de 23,2 y 241 casos por cada 100000 habitantes, respectivamente [134]. Las artralgias son la manifestación inicial en el $50 \%$ de los casos y están presentes hasta en el $95 \%$ de los pacientes durante el curso de la enfermedad. Pueden migrar de una articulación a otra, el compromiso suele ser simétrico y poliarticular con predilección por las rodillas, el carpo y articulaciones interfalángicas, en especial la interfalángica proximal El compromiso monoarticular es inusual y la rigidez matutina es corta $[135,136]$.

\section{Menopausia}

Las artralgias son experimentadas por la mitad de las mujeres durante la menopausia [137]. Aparecen acompañadas de dolores musculares difusos, dolor lumbar y depresión [138-140]. Otros síntomas son trastornos cognitivos y del sueño, sequedad vaginal, mialgias, disminución de la función sexual, oleadas de calor y eccema climatérico [141-142].

\section{Hiperlaxitud ligamentaria}

EL 2\% de la población general tiene características de hiperlaxitud ligamentaria [143]. Es más frecuente en población infantil, aunque puede presentarse en adultos jóvenes, en especial en mujeres. Las artralgias, mialgias y fatiga son la forma de presentación más frecuente en los adultos [144]. Las artralgias son oligo o poliarticulares. Otros hallazgos son piel elástica, cicatrices delgadas como papel, estrías atróficas, hábito marfanoide, hernias abdominales, prolapso genital, venas varicosas, signo de Gorlin (tocarse nariz con la punta de la lengua) y ausencia de frenillo lingual [145].

\section{Hepatitis $\mathbf{C}$}

Las artralgias son la manifestación extra hepática más común de la hepatitis C y se presentan en el $23 \%$ de los casos [146, 147]. Son similares a las de la AR (simétricas y de pequeñas articulaciones), aunque no causan deformidad y la rigidez matutina es corta [146,

148]. El factor reumatoide es positivo en el 40 a $50 \%$ de los pacientes [149]. Otros síntomas de la infección crónica son fatiga, debilidad y dolor abdominal en hipocondrio derecho [146].

\section{Medicamentos}

Los inhibidores de la DPP4 pueden causar dolor articular severo e incapacitante desde el primer día de inicio o incluso años más tarde y los síntomas ceden con la suspensión de este. Al reiniciar el medicamento se vuelve a presentar el dolor articular y este efecto aplica para otros fármacos de la misma clase $[150,151]$.

La isoniazida causa síndrome mano-hombro luego de cuatro semanas de iniciado el tratamiento. Se presenta dolor de inicio súbito, sensibilidad y rigidez en la articulación de la mano, acompañado de dolor en el hombro y mialgias [152].

El dolor articular, muscular y óseo con los bifosfonatos pueden llegar a ser severo e incapacitante [153]. También se ha reportado artralgias con el uso de estatinas y omeprazol [154, 155].

\section{El paciente quien refiere: "tengo piquiña en todo el cuerpo"}

Cerca del 10 a $50 \%$ de los pacientes con prurito sin una causa evidente dermatológica tienen patología sistémica [156].

\section{Causas de prurito son:}

- Xerosis, escabiosis, dermatitis atópica, dermatitis alérgica por contacto, urticaria, pénfigo bulloso, dermatitis herpetiforme, psoriasis, prurigo nodular y mastocitosis.

- Foliculitis, pediculosis, varicela, cándida, impétigo y dermatosis por VIH.

- Parasitosis.

- Medicamentos.

- Litiasis biliar, pancreatitis, cáncer de páncreas, hepatitis y metástasis hepáticas.

- Insuficiencia renal crónica.

- Síndrome carcinoide, linfomas y mieloma múltiple.

- Hipo e hipertiroidismo, hiperparatiroidismo y diabetes mellitus.

- Síndrome mielodisplásico.

- Esclerosis múltiple, tumores cerebrales, notalgia parestetica, posterior a varicela zoster y neuropatía de fibra pequeña.

- Prurito braquioradial.

Otras causas a considerar son:

\section{Deficiencia de hierro}

La deficiencia de hierro con o sin anemia es la causa más frecuente de prurito por enfermedad sistémica [157]. Otras manifestaciones son glositis y quelitis angular. El prurito no mejora con antihistamínicos, pero si lo hace con la suplementación con hierro $[158,159]$.

\section{Cirrosis biliar primaria}

El 20 a $70 \%$ de los pacientes presentan prurito [37], y en el $50 \%$ puede ser la manifestación inicial [159]. Se asocia a hiperlipidemia, hipotiroidismo, síndrome de Sjögren y esclerodermia [37]. El 50\% de los pacientes tienen hiperpigmentación [39].

\section{Micosis fungoide}

Tiene una incidencia de 6,4 personas por millón de habitantes. Los pacientes con linfoma de células T cutáneo experimentan prurito en el 66 a $88 \%$ de los casos, es el síntoma más frecuente y suele empeorar en los estadios tardíos de la enfermedad. El prurito puede anteceder la aparición de las placas cutáneas hasta por 15 meses [160], estas son descamativas y pueden llegar a formar lesiones ulceradas.

\section{Policitemia vera}

Tiene una incidencia de 1,9 a 2,8 casos por 100000 habitantes [161]. El prurito se presenta en el $65 \%$ de pacientes, se produce por el contacto con el agua caliente sin cambios visibles en la piel, dura entre 10 a 120 minutos y puede preceder el desarrollo de la enfermedad hasta por 13 años [162]. Otras síntomas son fatiga, dolor óseo, disnea, cefalea, vértigo, tinitus, diaforesis, insomnio, disminución del estado de ánimo, problemas de atención y trastornos sexuales [162].

\section{Polineuropatía}

El $8 \%$ a $17 \%$ de los casos de prurito crónico son de origen neuropático. Se presenta en un tercio de pacientes con polineuropatía periférica. La diabetes, VIH, quimioterapia y compresión radicular por cáncer son las causas frecuentes de polineuropatía y prurito. Puede presentarse de forma localizada en cara, garganta, oídos, mandíbula, tronco y extremidades en el recorrido de una raíz nerviosa y de manera generalizada en forma de neuropatía de fibra pequeña $[163,164]$.

\section{Hipo e hipertiroidismo}

El hipotiroidismo tiene una prevalencia entre 2 y $4,6 \%$ y es más alta para el hipotiroidismo subclínico (10\%). El hipertiroidismo tiene una 
prevalencia de $1,3 \%$ [165]. Las enfermedades tiroideas, en especial la enfermedad de Graves, tienen un amplio rango de manifestaciones en piel, de las cuales las más frecuentes son urticaria crónica y prurito $(6,8 \%)$, alopecia y vitíligo, las cuales mejoran con el tratamiento de la patología tiroidea [166].

\section{Colestasis del embarazo}

E1 20\% de las embarazadas presentan prurito [167]. Las causas son pápulas y placas urticariales, colestasis intrahepática, penfigoide gestacional y erupción atópica del embarazo. La colestasis intrahepática tiene una alta frecuencia en regiones de Sudamérica, en especial Chile (15-28\%) [168]. Esta se presenta después del segundo trimestre, el prurito inicia de forma súbita en las palmas y plantas, luego se generaliza de forma rápida y empeora en la noche. Sólo el $10 \%$ de las pacientes tiene ictericia [167]. Hay riesgo de desarrollar esteatorrea y malabsorción de vitaminas liposolubles. En pacientes diagnosticadas con colestasis del embarazo que solo tienen prurito puede presentarse progresión a hígado graso agudo en días a semanas $[169,170]$.

\section{Prurito acuagénico}

Es aquel causado por el contacto con el agua. El 30\% de los casos se asocian con trastornos linfoproliferativos y hematológicos, como policitemia vera, trombocitosis esencial, síndrome mielodisplásico, leucemia linfoblástica aguda, hemocromatosis y linfoma de células T no Hodgkin. El prurito puede preceder varios años el desarrollo de estas neoplasias. El 25\% de casos se asocia con intolerancia a la lactosa y en el resto de los casos no se logra determinar la causa $[171,172]$.

\section{Neuromielitis óptica}

Tiene una prevalencia de 0,5 a 10 casos por 100000 habitantes [173]. El compromiso medular se manifiesta como una mielitis transversa asociada a síntomas sensitivos como parestesias, dolor y prurito, el cual es reportado en el $27 \%$ de pacientes y cuando se presenta puede ser una "bandera roja" que indica una recaída de la enfermedad [174]

\section{Prurito senil}

La prevalencia del prurito aumenta con la edad, el 19,5\% de pacientes mayores de 85 años experimentan prurito y entre las principales causas están la xerosis, el aumento de la sensibilidad de la piel a la histamina, altas tasas de comorbilidad y el uso de medicamentos. El diagnóstico de prurito idiopático senil debe hacerse una vez se hayan excluido enfermedades sistémicas, medicamentos y neoplasias como causa del mismo $[175,176]$.

\section{VIH}

El prurito severo se ha reportado en el $45 \%$ de pacientes con VIH, ocurre en etapas avanzadas de la enfermedad y se asocia con una rápida disminución del conteo de linfocitos $\mathrm{CD} 4$, por lo que puede ser considerado un marcador cutáneo de la progresión de la enfermedad [177].

\section{Esclerosis múltiple}

El prurito se presenta en el 5\% de pacientes, en forma paroxística, con ataques cortos de varios segundos a minutos de duración y en diferentes localizaciones [178].

\section{Mielofibrosis}

Tiene una prevalencia de 1,5 casos por 100000 habitantes. El prurito se ha reportado en el $16 \%$ de los casos. El síntoma reportado con más frecuencia es la fatiga severa y otros síntomas son la fiebre de bajo grado, dolor óseo, diaforesis nocturna y pérdida de peso [179].

\section{El familiar quien refiere: "mantiene ansioso" o "se comporta raro"}

La ansiedad puede presentarse con diaforesis, palpitaciones, disnea, dolor torácico, mareo, temblor, calores o sensación de enfriamiento, diarrea, irritabilidad y polaquiuria. Se debe pensar en una etiología orgánica cuando: se presenta en mayores de 35 años, no hay antecedentes familiares de trastorno de ansiedad, no hay antecedentes personales de trastorno de ansiedad en la infancia (fobias, ansiedad por separación), eventos estresores o comportamiento evasivo y hay pobre respuesta a los ansiolíticos $[180,181]$.

Causas de ansiedad son:

- Hipo e hipertiroidismo.

- Hipercortisolismo e hipoglucemia

- Intoxicaciones con estimulantes (café, anfetaminas).

- Síndrome de abstinencia al alcohol o sedantes.

- Tumores cerebrales.

- Disfunción vestibular.

- $\quad$ ICC, EPOC y embolia pulmonar.

- Hiperadrenalismo.

- Deficiencia de vitamina B12.

Los cambios en la personalidad o el comportamiento pueden ser muy sutiles, consisten en cambios respecto a la personalidad previa o una acentuación de esta $[182,183]$. Son fácilmente confundidos con trastornos psiquiátricos dada la similitud de sus manifestaciones [183]. Las causas orgánicas de cambios en la personalidad son:

- Síndromes del lóbulo frontal.

- Enfermedad de Parkinson.

- $\quad$ Enfermedad de Huntington, demencia tipo Alzheimer y otras demencias.

- Esclerosis múltiple.

- $\quad \mathrm{ECV}$, meningitis y encefalitis viral.

- Síndromes paraneoplásicos.

- $\quad$ Encefalopatía por VIH.

- Lesión hemisférica derecha.

- Intoxicaciones.

Otras causas de ansiedad o cambios de la personalidad a considerar son:

\section{Hipercalcemia}

El 66\% de los pacientes con hipercalcemia crónica presentan síntomas de ansiedad [184]. Puede presentarse también depresión y disfunción cognitiva. El hiperparatiroidismo y la malignidad son las causas más comunes. La hipercalcemia leve puede ser asintomática, valores más altos de calcio se manifiestan con poliuria, polidipsia, deshidratación, anorexia, nausea y debilidad muscular $[185,186]$.

\section{Síndrome serotoninérgico}

En dosis única o en combinación, los inhibidores de la recaptación de serotonina asociados a metoclopramida, tramadol, dextrometorfano, hierba de San Juan, trazodona, antidepresivos tricíclicos, carbamazepina, ácido valproico, litio, triptanes y drogas recreativas pueden generar síndrome serotoninérgico [187]. La triada de síntomas incluye estado mental alterado (ansiedad, agitación, desorientación), 
anormalidades neuromusculares (temblor, clonus, rigidez muscular) e hiperactividad autonómica (hipertensión y taquicardia). Desde las formas leves aparece midriasis, hiperreflexia rotuliana, fiebre, diaforesis, ansiedad e inquietud [188]

\section{Neurosífilis}

Las manifestaciones psiquiátricas se presentan en el 33 a $86 \%$ de los casos. Estas incluyen mania, depresión, cambios en la personalidad, comportamientos inusuales, delirium, demencia y psicosis por lo que puede llegar a simular cualquier trastorno psiquiátrico. La mitad de los casos presentan alucinaciones y cambios en la personalidad [189. 190]. Es posible que solo existan las alteraciones psiquiátricas y cognitivas sin hallazgos en el examen neurológico [191]. Las manifestaciones pueden ser tan tardías como 70 años y por lo cual el paciente puede no recordar o asociar el episodio de infección primaria [192]

\section{Enfermedad ateroembólica}

La enfermedad ateroembolica puede remedar en su totalidad un trastorno psiquiátrico primario. Se deben recordar los periodos de aparición de los trastornos psiquiátricos primarios que usualmente son entre $\operatorname{los} 15$ a 25 años y posteriormente 45 a 55 años [193]. La aparición de episodios maniacos por encima de esta edad obliga a pensar en un fondo orgánico. No son necesarios los síntomas de focalización neurológica. El trastorno depresivo mayor se presenta en el $30 \%$ de los pacientes [194]. Otros manifestaciones psiquiátricas posteriores a ECV son: psicosis, reacción catastrófica (síntomas de frustración y desespero), trastornos de ansiedad, afecto pseudobulbar (llanto y risa frecuentes y de fácil provocación), apatía y cambios de personalidad $[195,196]$

\section{Demencia fronto-temporal}

La incidencia en pacientes entre 45 a 64 años es de 3,5 casos por 100000 habitantes [197]. Es la demencia de inicio más temprano, con rango de aparición entre los 33 y 80 años, el 10\% de los casos aparece antes de los 45 años [198, 199]. Trastornos del comportamiento como abandono de la higiene personal, desinhibición, apatía, frialdad social, tendencia a llevarse objetos a la boca (hiperoralidad) y comportamientos obsesivos-compulsivos se observan en más de la mitad de los pacientes $[199,200]$. Se confunde con frecuencia con el paciente deprimido.

\section{Delirium por medicamentos}

Algunos medicamentos como benzodiazepinas, antidepresivos tricíclicos y antipsicóticos son reconocidos por causar delirium, pero hay otros medicamentos poco conocidos con efecto anticolinérgico como la furosemida, betabloqueadores, antiinflamatorios no esteroideos (AINES), valeriana, ranitidina, antibióticos, antivirales e hipoglicemiantes que también pueden producir delirium [201,202].

\section{Encefalitis límbica}

La incidencia de cualquier tipo de encefalitis es de 8 casos por cada 100000 personas, de las cuales 40 a $50 \%$ son de origen desconocido [203]. La causa autoinmune es la tercera causa más frecuente de encefalitis y puede aparecer a cualquier edad. Los síntomas cardinales son: cambios en el comportamiento, psicosis, convulsión, déficit cognitivo y de memoria, movimientos anormales, disautonomía (hipotensión y taquicardia) y disminución del nivel de conciencia [204]. Los síntomas neurológicos preceden el hallazgo del tumor en semanas a meses. Las neoplasias más comúnmente asociadas son el cáncer de pulmón [205], tumores testiculares, timoma, teratoma de ovario, cáncer de mama y linfoma tipo Hodgkin [206]. Los estudios de imágenes son normales o inespecíficos [204].

\section{Ludopatía por dopaminérgicos}

La ludopatía está presente en el 0,4 a 3,4\% de la población adulta [207]. Es una reacción adversa a medicamentos dopaminérgicos y aparece en el $17 \%$ de pacientes con enfermedad de Parkinson tratados con estos agentes [207]. El paciente presenta dificultad para controlar los impulsos, la cual incluye hipersexualidad que puede afectar hasta al $90 \%$ de los pacientes, compras patológicas, comer compulsivamente y dedicación excesiva a los hobbies [208] El pramipexole y aripiprazole son los medicamentos con mayor asociación [209].

\section{Epilepsia del lóbulo temporal}

Es la causa más común de epilepsias localizadas. Se caracteriza por la presencia de auras aisladas o que preceden a una crisis motora focal, se describen como sensación de vacío en epigastrio, déjà o jamais vu, sensación de miedo, alucinaciones visuales, auditivas complejas, gustativas u olfatorias [210]. Los síntomas neuropsiquiátricos incluyen trastornos cognitivos, problemas de memoria, depresión y ansiedad [211]. La esclerosis mesial hipocampal es la causa más frecuente. El $80 \%$ inician antes de los 16 años, pero puede iniciar incluso a los 32 años de edad [212].

\section{Intoxicación por mercurio}

En Colombia, entre el 2007 y 2011 se reportaron 450 casos confirmados de intoxicación por mercurio [213]. La exposición crónica a bajas concentraciones de mercurio elemental puede producir manifestaciones neuropsiquiátricas, de las cuales se destaca el temblor e insomnio. Cuadros más avanzados son llamados "eretismo mercurial" caracterizado por cambios en la personalidad, ansiedad, irritabilidad, excitabilidad, fobia, timidez patológica, pérdida de memoria, depresión, fatiga y debilidad. Son fuentes comunes de mercurio elemental: la manufactura o manipulación de termómetros y barómetros, minería de oro artesanal, amalgamas dentales y refinerías de metales [214].

\section{Feocromocitoma}

Cefalea, palpitaciones, dolor torácico y sudoración son manifestaciones frecuentes. El paciente puede tener hipertensión en crisis, sostenida o presentar episodios de hipotensión [215]. Tiene un gran número de manifestaciones por lo que se conoce como el gran simulador de situaciones de estrés [216]. En ocasiones es difícil distinguirlo del paciente ansioso o del trastorno de pánico [217].

\section{Alcoholismo}

No todos los pacientes reportan el consumo de alcohol en la consulta. Las personas que consumen alcohol tienen tres veces más riesgo de tener cualquier trastorno de ansiedad [218]. El 80\% tienen síntomas depresivos, los cuales pueden preceder el consumo, desarrollarse luego del consumo crónico o aparecer luego de una intoxicación. También puede presentarse alucinaciones visuales durante la abstinencia, alucinosis y delirios similares a los de pacientes con esquizofrenia [219]. Las consecuencias a largo plazo también incluyen trastornos de la memoria, deterioro cognitivo e insomnio [220, 221].

\section{Porfiria}

En el adulto la porfiria intermitente aguda y variegata están involucradas en episodios agudos neuroviscerales. Las manifestaciones psiquiátricas durante el ataque agudo son ansiedad, depresión, fobias, agitación, delirium y alteración del estado de conciencia. Casi la mitad de los pacientes presentan ansiedad, irritabilidad y depresión de manera continua no relacionada con los ataques agudos [222].

\section{Conclusiones}

Muchos síntomas pueden llegar a ser de difícil interpretación clínica, es necesario reconocer causas poco usuales cuando se han descartado patologías más frecuentes, cuando se está frente a un paciente que ha consultado en múltiples ocasiones o en el que no se ha logrado un diagnóstico claro. 
Conflicto de intereses: Los autores declaramos que no tenemos conflicto de intereses.

\section{Referencias}

1. Shen J, Barbera J, Shapiro CM. Distinguishing sleepiness and fatigue: focus on definition and measurement. Sleep medicine reviews. 2006;10(1):63-76.

2. Mulligan T, Frick M, Zuraw Q, Stemhagen A, McWhirter C. Prevalence of hypogonadism in males aged at least 45 years: the HIM study. International journal of clinical practice. 2006;60(7):762-

3. Scovell JM, Ramasamy R, Wilken N, Kovac JR, Lipshultz LI. Hypogonadal symptoms in young men are associated with a serum total testosterone threshold of $400 \mathrm{ng} / \mathrm{dL}$. BJU international. 2015;116(1):142-6.

4. Seftel A. Male hypogonadism. Part I: Epidemiology of hypogonadism. International journal of impotence research. 2006;18(2):115.

5. Kumar P, Kumar N, Thakur DS, Patidar A. Male hypogonadism: Symptoms and treatment. Journal of advanced pharmaceutical technology \& research. 2010;1(3):297.

6. High Jr WM, Briones-Galang M, Clark JA, Gilkison C, Mossberg KA, Zgaljardic DJ, et al. Effect of growth hormone replacement therapy on cognition after traumatic brain injury. Journal of neurotrauma. 2010;27(9):1565-75

7. Norrie J, Heitger M, Leathem J, Anderson T, Jones R, Flett R. Mild traumatic brain injury and fatigue: a prospective longitudinal study. Brain injury. 2010;24(13-14):1528-38.

8. Draper K, Ponsford J. Cognitive functioning ten years following traumatic brain injury and rehabilitation. Neuropsychology. 2008;22(5):618.

9. Johansson B, Rönnbäck L. Long-lasting mental fatigue after traumatic brain injury-a major problem most often neglected diagnostic criteria, assessment, relation to emotional and cognitive problems, cellular background, and aspects on treatment. Traumatic brain injury: InTech; 2014.

10. Gupta V. Adult growth hormone deficiency. Indian journal of endocrinology and metabolism. 2011;15(Suppl3):S197.

11. Gómez S, Álvarez Y, Puerto JA. Miastenia Gravis: una visión actual de la enfermedad. Medicas UIS. 2013;26(3):13-22.

12. Jayam Trouth A, Dabi A, Solieman N, Kurukumbi M, Kalyanam J. Myasthenia gravis: a review. Autoimmune diseases. 2012;2012.

13. Gilhus NE. Myasthenia Gravis. New England Journal of Medicine. 2016;375(26):2570-81.

14. Nair AG, Patil-Chhablani P, Venkatramani DV, Gandhi RA. Ocular myasthenia gravis: A review. Indian journal of ophthalmology. 2014;62(10):985

15. Sih M, Soliven B, Mathenia N, Jacobsen J, Rezania K. Head $\square$ drop: A frequent feature of late $\square$ onset myasthenia gravis Muscle \& nerve. 2017;56(3):441-4

16. Turner C. A review of myasthenia gravis: Pathogenesis, clinical features and treatment. Current Anaesthesia and Critical Care. 2007;18(1):15-23

17. Motomura M, Nakata R, Shiraishi H. Lambert-Eaton myasthenic syndrome: Clinical review. Clinical and Experimental Neuroimmunology. 2016;7(3):238-45.

18. O'suilleabhain P, Low PA, Lennon VA. Autonomic dysfunction in the Lambert-Eaton myasthenic syndrome Serologic and clinical correlates. Neurology. 1998;50(1):88-93.

19. Young JD, Leavitt JA. Lambert-Eaton myasthenic syndrome: ocular signs and symptoms. Journal of NeuroOphthalmology. 2016;36(1):20-2.

20. Muñoz-Mateo J, Álvarez-Vázquez M, FernándezRodríguez R, Fagundo-González O, Flores-Calvete J. Síndrome miasteniforme de Eaton-Lambert. Revisión y presentación de un caso. Rehabilitación. 2006;40(5):271-4.

21. Jiménez C. Estado actual de la esclerosis múltiple en Colombia. 2016

22. Braley TJ, Chervin RD. Fatigue in multiple sclerosis: mechanisms, evaluation, and treatment. Sleep. 2010;33(8):1061-7.

23. Čarnická Z, Kollár B, Šiarnik P, Krížová L, Klobučníková K, Turčáni P. Sleep disorders in patients with multiple sclerosis. Journal of clinical sleep medicine: JCSM: official publication of the American Academy of Sleep Medicine. 2015;11(5):553.

24. McAlpine D, Compston A. McAlpine's multiple sclerosis: Elsevier Health Sciences; 2005.

25. Lublin FD. Clinical features and diagnosis of multiple sclerosis. Neurologic clinics. 2005;23(1):1-15

26. Syndulko K, Jafari M, Woldanski A, Baumhefner RW, Tourtellotte WW. Effects of temperature in multiple sclerosis: a review of the literature. Journal of Neurologic Rehabilitation. 1996;10(1):2334.

27. Patel R, Shahane A. The epidemiology of Sjögren's syndrome. Clinical epidemiology. 2014;6:247.

28. Mariette X, Criswell LA. Primary Sjögren's Syndrome. New England Journal of Medicine. 2018;378(10):931-9.

29. Ng W-F, Bowman SJ. Primary Sjögren's syndrome: too dry and too tired. Rheumatology. 2010;49(5):844-53.

30. Godaert G, Hartkamp A, Geenen R, Garssen A, Kruize A, Bijlsma J, et al. Fatigue in daily life in patients with primary Sjögren's syndrome and systemic lupus erythematosus. Annals of the New York Academy of Sciences. 2002;966(1):320-6.

31. Gray EL, McKenzie DK, Eckert DJ. Obstructive sleep apnea without obesity is common and difficult to treat: evidence for a distinct pathophysiological phenotype. Journal of clinical sleep medicine: JCSM: official publication of the American Academy of Sleep Medicine. 2017;13(1):81

32. Gray EL, McKenzie DK, Eckert DJ. Obstructive Sleep Apnea without Obesity Is Common and Difficult to Treat: Evidence for a Distinct Pathophysiological Phenotype. Journal of clinical sleep medicine : JCSM : official publication of the American Academy of Sleep Medicine. 2017;13(1):81-8.

33. Konecny T, Kara T, Somers VK. Obstructive sleep apnea and hypertension: an update. Hypertension. 2014;63(2):203-9.

34. Dacal Quintas R, Tumbeiro Novoa M, Alves Perez MT, Santalla Martinez ML, Acuna Fernandez A, Marcos Velazquez P. Obstructive sleep apnea in normal weight patients: characteristics and comparison with overweight and obese patients. Archivos de bronconeumologia. 2013;49(12):513-7.

35. Kimoff RJ. When to suspect sleep apnea and what to do about it. Canadian Journal of Cardiology. 2015;31(7):945-8.

36. Kim WR, Lindor KD, Locke GR, Therneau TM, Homburger HA, Batts KP, et al. Epidemiology and natural history of primary biliary cirrhosis in a US community. Gastroenterology. 2000;119(6):1631-6.

37. Kaplan MM, Gershwin ME. Primary Biliary Cirrhosis. 
New England Journal of Medicine. 2005;353(12):1261-73.

38. Abbas G, Jorgensen RA, Lindor KD. Fatigue in primary biliary cirrhosis. Nature Reviews Gastroenterology and Hepatology. 2010;7(6):313.

39. Carey EJ, Ali AH, Lindor KD. Primary biliary cirrhosis. The Lancet. 2015;386(10003):1565-75.

40. Papierska L, Rabijewski M. Delay in Diagnosis of Adrenal Insufficiency Is a Frequent Cause of Adrenal Crisis. International Journal of Endocrinology. 2013;2013:482370.

41. Bornstein SR, Allolio B, Arlt W, Barthel A, Don-Wauchope A, Hammer GD, et al. Diagnosis and treatment of primary adrenal insufficiency: an endocrine society clinical practice guideline. The Journal of Clinical Endocrinology \& Metabolism. 2016;101(2):36489.

42. Baschetti R. Fibromyalgia, chronic fatigue syndrome, and Addison disease. Archives of internal medicine. 1999;159(20):2481-.

43. Baschetti R. Chronic fatigue syndrome: a form of Addison's disease. Journal of internal medicine. 2000;247(6):737-9.

44. Cogollo VC, Tous MG, Teherán CG, Mattar S. Fiebre Q: una zoonosis olvidada en Colombia. Revista Médica de Risaralda. $2013 ; 19(2)$

45. Tissot-Dupont H, Amadei M-A, Nezri M, Raoult D. Wind in November, Q fever in December. Emerging infectious diseases. 2004;10(7):1264.

46. Ledina D, Bradarić N, Milas I, Ivić I, Brncić N, Kuzmicić N. Chronic fatigue syndrome after Q fever. Medical science monitor. 2007;13(7):CS88-CS92.

47. Morroy G, Keijmel SP, Delsing CE, Bleijenberg G, Langendam M, Timen A, et al. Fatigue following acute Q-fever: A systematic literature review. PloS one. 2016;11(5):e0155884.

48. Hatchette TF, Marrie TJ. Atypical manifestations of chronic Q fever. Clinical infectious diseases. 2001;33(8):1347-51.

49. Katz BZ, Shiraishi Y, Mears CJ, Binns HJ, Taylor R. Chronic fatigue syndrome after infectious mononucleosis in adolescents. Pediatrics. 2009;124(1):189-93.

50. Becker LA. patients with infectious mononucleosis have long lasting fatigue, and poor physical functioning predicts delayed recovery. BMJ Evidence Based Medicine. 2003;8(3):92.

51. Heim C, Nater UM, Maloney E, Boneva R, Jones JF, Reeves WC. Childhood trauma and risk for chronic fatigue syndrome: association with neuroendocrine dysfunction. Archives of general psychiatry. 2009;66(1):72-80.

52. Taylor RR, Jason LA. Chronic fatigue, abuse-related traumatization, and psychiatric disorders in a community-based sample. Social science \& medicine. 2002;55(2):247-56.

53. Heim C, Wagner D, Maloney E, Papanicolaou DA, Solomon L, Jones JF, et al. Early adverse experience and risk for chronic fatigue syndrome: results from a population-based study. Archives of general psychiatry. 2006;63(11):1258-66.

54. Obstetricians ACo, Gynecologists. Adult manifestations of childhood sexual abuse. Committee Opinion No. 498. Obstet Gynecol. 2011;118:392-5.

55. Yeh MW, Ituarte $\mathrm{PH}$, Zhou $\mathrm{HC}$, Nishimoto S, Amy Liu I-L, Harari A, et al. Incidence and prevalence of primary hyperparathyroidism in a racially mixed population. The Journal of Clinical Endocrinology \& Metabolism. 2013;98(3):1122-9.

56. Turner JJ. Hypercalcaemia-presentation and management. Clinical Medicine. 2017;17(3):270-3.
57. Gonzaga CC, Calhoun DA. Resistant hypertension and hyperaldosteronism. Current hypertension reports. 2008;10(6):496.

58. Mulatero P, Stowasser M, Loh K-C, Fardella CE, Gordon $\mathrm{RD}$, Mosso L, et al. Increased diagnosis of primary aldosteronism, including surgically correctable forms, in centers from five continents. The Journal of Clinical Endocrinology \& Metabolism. 2004;89(3): 1045-50.

59. Kardalas E, Paschou SA, Anagnostis P, Muscogiuri G, Siasos G, Vryonidou A. Hypokalemia: a clinical update. Endocrine connections. 2018;7(4):R135-R46.

60. Schwartz WB, Relman AS. Effects of electrolyte disorders on renal structure and function. New England Journal of Medicine. 1967;276(7):383-9.

61. Goddard AF, James MW, McIntyre AS, Scott BB, British Society of G. Guidelines for the management of iron deficiency anaemia. Gut. 2011;60(10):1309-16.

62. Murray-Kolb LE, Beard JL. Iron treatment normalizes cognitive functioning in young women-. The American journal of clinical nutrition. 2007;85(3):778-87.

63. Verdon F, Burnand B, Stubi CF, Bonard C, Graff M, Michaud A, et al. Iron supplementation for unexplained fatigue in non-anaemic women: double blind randomised placebo controlled trial. Bmj. 2003;326(7399):1124.

64. Gupta V, Lee M. Central hypothyroidism. Indian journal of endocrinology and metabolism. 2011;15(Suppl2):S99.

65. Chakera AJ, Pearce SH, Vaidya B. Treatment for primary hypothyroidism: current approaches and future possibilities. Drug design, development and therapy. 2012;6:1 .

66. Leschziner GD. Restless legs syndrome. Sleep Disorders in Psychiatric Patients: Springer; 2018. p. 175-88.

67. Moreira N, Damasceno R, Medeiros C, De Bruin P, Teixeira C, Horta W, et al. Restless leg syndrome, sleep quality and fatigue in multiple sclerosis patients. Brazilian Journal of Medical and Biological Research. 2008;41(10):932-7.

68. Bertisch S. Restless Legs Syndrome. Annals of internal medicine. 2015;163(9):ITC1-ITC.

69. Corey HE, Eckstein D. Chapter 68 - Renal Tubular Acidosis. In: Ronco C, Bellomo R, Kellum JA, Ricci Z, editors. Critical Care Nephrology (Third Edition). Philadelphia: Content Repository Only!; 2019. p. 405-8.e1

70. Basu G, Sudhakar G, Mohapatra A. Renal tubular acidosis. Clinical Queries: Nephrology. 2013;2(4):166-78.

71. Emmett M, Palmer BF. Etiology and diagnosis of distal (type 1) and proximal (type 2) renal tubular acidosis: Uptodate; 2018 [Available from: https://www.uptodate.com/contents/etiologyand-diagnosis-of-distal-type-1-and-proximal-type-2-renal-tubularacidosis.

72. Hampl JS, Taylor CA, Johnston CS. Vitamin C deficiency and depletion in the United States: the third national health and nutrition examination survey, 1988 to 1994 . American journal of public health. 2004;94(5):870-5.

73. Léger D. Scurvy: Reemergence of nutritional deficiencies. Canadian Family Physician. 2008;54(10):1403-6.

74. Bennett SE, Schmitt WP, Stanford FC, Baron JM. Case 22-2018: A 64-Year-Old Man with Progressive Leg Weakness, Recurrent Falls, and Anemia. New England Journal of Medicine. 2018;379(3):282-9.

75. Shumway NK, Cole E, Fernandez KH. Neurocutaneous disease: Neurocutaneous dysesthesias. Journal of the American 
Academy of Dermatology. 2016;74(2):215-28.

76. Gregg EW, Sorlie P, Paulose-Ram R, Gu Q, Eberhardt MS, Wolz M, et al. Prevalence of lower-extremity disease in the US adult population $\geq 40$ years of age with and without diabetes: 1999-2000 National Health and Nutrition Examination Survey. Diabetes care. 2004;27(7):1591-7.

77. Hovaguimian A, Gibbons CH. Diagnosis and treatment of pain in small-fiber neuropathy. Current pain and headache reports. 2011;15(3):193-200.

78. Themistocleous AC, Ramirez JD, Serra J, Bennett DL. The clinical approach to small fibre neuropathy and painful channelopathy. Practical neurology. 2014;14(6):368-79.

79. Brito A, Mujica-Coopman MF, Olivares M, Lopez de Romana D, Cori H, Allen LH. Folate and vitamin B12 status in Latin America and the Caribbean: an update. Food and nutrition bulletin. 2015;36(2_suppl):S109-S18.

80. McLean E, de Benoist B, Allen LH. Review of the magnitude of folate and vitamin B12 deficiencies worldwide. Food and nutrition bulletin. 2008;29(2_suppl1):S38-S51.

81. Pawlak R, Parrott SJ, Raj S, Cullum-Dugan D, Lucus D. How prevalent is vitamin B12 deficiency among vegetarians? Nutrition reviews. 2013;71(2):110-7.

82. Stabler SP. Vitamin B12 Deficiency. New England Journal of Medicine. 2013;368(2):149-60.

83. Saperstein DS, Barohn RJ. Peripheral neuropathy due to cobalamin deficiency. Current treatment options in neurology. 2002;4(3):197-201.

84. Hammond N, Wang Y, Dimachkie M, Barohn R. Nutritional neuropathies. Neurologic clinics. 2013;31(2):477.

85. Staff NP, Windebank AJ. Peripheral neuropathy due to vitamin deficiency, toxins, and medications. Continuum: Lifelong Learning in Neurology. 2014;20(5 Peripheral Nervous System Disorders): 1293.

86. Garriga XM. Definición, etiopatogenia, clasificación y formas de presentación. Atención primaria. 2014;46:3-10.

87. Mullin J, Shedid D, Benzel E. Overview of cervical spondylosis pathophysiology and biomechanics. World Spinal Column J. 2011;2(3):89-97.

88. Binder AI. Cervical spondylosis and neck pain. BMJ: British Medical Journal. 2007;334(7592):527.

89. Alarcon WA. Elevated Blood Lead Levels Among Employed Adults-United States, 1994-2013. MMWR Morbidity and mortality weekly report. 2016;63.

90. Control CfD, Prevention. Blood lead levels--United States, 1999-2002. MMWR Morbidity and mortality weekly report. 2005;54(20):513.

91. Thomson RM, Parry GJ. Neuropathies associated with excessive exposure to lead. Muscle \& nerve. 2006;33(6):732-41.

92. Wani AL, Ara A, Usmani JA. Lead toxicity: a review. Interdisciplinary toxicology. 2015;8(2):55-64.

93. Hu H, Aro A, Payton M, Korrick S, Sparrow D, Weiss ST, et al. The relationship of bone and blood lead to hypertension: the Normative Aging Study. Jama. 1996;275(15):1171-6.

94. Shih R, Glass T, Bandeen-Roche K, Carlson M, Bolla K, Todd A, et al. Environmental lead exposure and cognitive function in community-dwelling older adults. Neurology. 2006;67(9):1556-62.
95. Eum K-D, Korrick SA, Weuve J, Okereke O, Kubzansky $\mathrm{LD}, \mathrm{Hu} \mathrm{H}$, et al. Relation of cumulative low-level lead exposure to depressive and phobic anxiety symptom scores in middle-age and elderly women. Environmental health perspectives. 2012;120(6):817.

96. Martínez MLO, Duran MEM, García OEP, Bonilla HQ, Pérez SF. Protocolo de Vigilancia en Salud Pública LEPRA.

97. Nascimento OJ. Leprosy neuropathy: clinical presentations. Arquivos de neuro-psiquiatria. 2013;71(9B):661-6.

98. Reni L, Noto S, Schreuder PA. The leprosy neuropathy. Leprosy: Springer; 2012. p. 163-79.

99. de Freitas MR, Said G. Leprous neuropathy. Handbook of clinical neurology. 115: Elsevier; 2013. p. 499-514.

100. Collins MP, Hadden RD. The nonsystemic vasculitic neuropathies. Nature Reviews Neurology. 2017;13(5):302.

101. Gwathmey KG, Burns TM, Collins MP, Dyck PJB Vasculitic neuropathies. The Lancet Neurology. 2014;13(1):67-82.

102. Gorson KC. Vasculitic neuropathies: an update. The neurologist. 2007;13(1):12-9.

103. Blaes F. Diagnosis and therapeutic options for peripheral vasculitic neuropathy. Therapeutic advances in musculoskeletal disease. 2015;7(2):45-55.

104. Gøransson LG, Herigstad A, Tjensvoll AB, Harboe E, Mellgren SI, Omdal R. Peripheral neuropathy in primary Sjögren syndrome: a population-based study. Archives of Neurology. 2006;63(11):1612-5.

105. Birnbaum J. Peripheral nervous system manifestations of Sjögren syndrome: clinical patterns, diagnostic paradigms, etiopathogenesis, and therapeutic strategies. The neurologist. 2010;16(5):287-97.

106. Mori K, Iijima M, Koike H, Hattori N, Tanaka F, Watanabe $\mathrm{H}$, et al. The wide spectrum of clinical manifestations in Sjögren's syndrome-associated neuropathy. Brain. 2005;128(11):2518-34.

107. Pavlakis P, Alexopoulos H, Kosmidis M, Mamali I, Moutsopoulos H, Tzioufas A, et al. Peripheral neuropathies in Sjögren's syndrome: a critical update on clinical features and pathogenetic mechanisms. Journal of autoimmunity. 2012;39(12):27-33.

108. Ramanujam VMS, Anderson KE. Porphyria diagnosticspart 1: a brief overview of the porphyrias. Current protocols in human genetics. 2015:17.20. 1-17.20. 6 .

109. Tracy JA, Dyck PJB. Porphyria and its neurologic manifestations. Handbook of clinical neurology. 120: Elsevier; 2014. p. 839-49.

110. Albers JW, Fink JK. Porphyric neuropathy. Muscle \& nerve. 2004;30(4):410-22.

111. Ruthirago D, Julayanont P, Rassameehiran S. Acute porphyrias and porphyric neuropathy. The Southwest Respiratory and Critical Care Chronicles. 2016;4(15):21-31.

112. Gilden D, Cohrs RJ, Mahalingam R, Nagel MA. Neurological disease produced by varicella zoster virus reactivation without rash. Varicella-zoster Virus: Springer; 2010. p. 243-53.

113. Lewis G. Zoster sine herpete. British Medical Journal. 1958;2(5093):418.

114. García-González AI, Rosas-Carrasco O. Herpes zoster (HZ) y neuralgia posherpética (NPH) en el adulto mayor: particularidades en la prevención, el diagnóstico y el tratamiento. Gaceta Médica de México. 2017;153(1):92-101. 
115. Wolf P. Epilepsy and the Sensory Systems. Epilepsy currents. 2016;16(6):369-72

116. Di Bonaventura C, Giallonardo AT, Fattouch J, Manfredi M. Symptoms in focal sensory seizures: clinical and electroencephalographic features. Seizure-European Journal of Epilepsy. 2005;14(1):1-9.

117. Erickson JC, Clapp LE, Ford G, Jabbari B. Somatosensory auras in refractory temporal lobe epilepsy. Epilepsia. 2006;47(1):2026.

118. Kannan MA, Challa S, Kandadai RM, Uppin MS, Jabeen SA, Borgohain R. Series of paraneoplastic vasculitic neuropathy: a rare, potentially treatable neuropathy. Neurology India. 2015;63(1):30.

119. Vincent D, Dubas F, Hauw J, Godeau P, Lhermitte F, Buge $\mathrm{A}$, et al. Nerve and muscle microvasculitis in peripheral neuropathy: a remote effect of cancer? Journal of Neurology, Neurosurgery \& Psychiatry. 1986;49(9):1007-10.

120. Li Y, Valent J, Soltanzadeh P, Thakore N, Katirji B. Diagnostic challenges in POEMS syndrome presenting with polyneuropathy: A case series. Journal of the neurological sciences. 2017:378:170-4

121. Nasu S, Misawa S, Sekiguchi Y, Shibuya K, Kanai K, Fujimaki Y, et al. Different neurological and physiological profiles in POEMS syndrome and chronic inflammatory demyelinating polyneuropathy. J Neurol Neurosurg Psychiatry. 2012:jnnp-2011301706 .

122. Dispenzieri A, Kyle RA. Neurological aspects of multiple myeloma and related disorders. Best practice \& research Clinical haematology. 2005;18(4):673-88.

123. Naddaf E, Dispenzieri A, Mandrekar J, Mauermann ML. Clinical spectrum of Castleman disease-associated neuropathy. Neurology. 2016;87(23):2457-62

124. Dispenzieri A, Armitage JO, Loe MJ, Geyer SM, Allred J, Camoriano JK, et al. The clinical spectrum of Castleman's disease. American journal of hematology. 2012;87(11):997-1002.

125. Nobile-Orazio E, Marmiroli P, Baldini L, Spagnol G, Barbieri S, Moggio M, et al. Peripheral neuropathy in macroglobulinemia Incidence and antigen $\square$ specificity of $\mathrm{M}$ proteins. Neurology. 1987;37(9):1506-

126. Baehring JM, Hochberg EP, Raje N, Ulrickson M, Hochberg FH. Neurological manifestations of Waldenström macroglobulinemia Nature Reviews Neurology. 2008;4(10):547.

127. Vigliani M-C, Magistrello M, Polo P, Mutani R, Chiò A Risk of cancer in patients with Guillain-Barre syndrome (GBS). Journal of neurology. 2004;251(3):321-6.

128. Hadjimichael O, Kerns RD, Rizzo MA, Cutter G, Vollmer T. Persistent pain and uncomfortable sensations in persons with multiple sclerosis. Pain. 2007;127(1-2):35-41.

129. Scott TF, Bhagavatula K, Snyder PJ, Chieffe C. Transverse myelitis comparison with spinal cord presentations of multiple sclerosis. Neurology. 1998;50(2):429-33

130. Carvalho AG, Fernandez-Herlihy L. The Differential Diagnosis of Arthralgia. Medical Clinics of North America. $1963 ; 47(2): 511-21$

131. Michet CJ, Matteson EL. Polymyalgia rheumatica. Bmj. 2008;336(7647):765-9

132. González-Gay MA, Matteson EL, Castañeda S. Polymyalgia rheumatica. The Lancet. 2017;390(10103):1700-12.

133. Helfgott SM, Kieval RI. Polymyalgia rheumatica in patients with a normal erythrocyte sedimentation rate. Arthritis \&
Rheumatology. 1996;39(2):304-7.

134. Rees F, Doherty M, Grainge MJ, Lanyon P, Zhang W. The worldwide incidence and prevalence of systemic lupus erythematosus: a systematic review of epidemiological studies. Rheumatology. 2017;56(11):1945-61.

135. Cojocaru M, Cojocaru IM, Silosi I, Vrabie CD. Manifestations of systemic lupus erythematosus. Maedica. 2011;6(4):330

136. Mahmoud K, Zayat A, Vital EM. Musculoskeletal manifestations of systemic lupus erythmatosus. Current opinion in rheumatology. 2017;29(5):486-92.

137. Magliano M. Menopausal arthralgia: Fact or fiction. Maturitas. 2010;67(1):29-33.

138. Alexander JL, Dennerstein L, Woods NF, Halbreich U, Kotz K, Richardson G, et al. Arthralgias, bodily aches and pains and somatic complaints in midlife women: etiology, pathophysiology and differential diagnosis. Expert review of neurotherapeutics. 2007;7(sup1):S15-S26.

139. Kaunitz AM. Should new-onset arthralgia be considered a menopausal symptom? Menopause. 2013;20(6):591-3.

140. Pérez JAM, Garcia FC, Palacios S, Pérez M. Epidemiology of risk factors and symptoms associated with menopause in Spanish women. Maturitas. 2009;62(1):30-6.

141. Santoro N, Epperson CN, Mathews SB. Menopausal symptoms and their management. Endocrinology and Metabolism Clinics. 2015;44(3):497-515.

142. Martin KA, Manson JE. Approach to the patient with menopausal symptoms. The Journal of Clinical Endocrinology \& Metabolism. 2008;93(12):4567-75.

143. Hakim AJ, Sahota A. Joint hypermobility and skin elasticity: the hereditary disorders of connective tissue. Clinics in Dermatology. 2006;24(6):521-33

144. Castori M, Sperduti I, Celletti C, Camerota F, Grammatico P. Symptom and joint mobility progression in the joint hypermobility syndrome (Ehlers-Danlos syndrome, hypermobility type). Clin Exp Rheumatol. 2011;29(6):998-1005.

145. Grahame R. Joint hypermobility syndrome pain. Current pain and headache reports. 2009;13(6):427.

146. Kemmer NM, Sherman KE. Hepatitis C-related arthropathy: Diagnostic and treatment considerations. The Journal of musculoskeletal medicine. 2010;27(9):351.

147. Mariette X. Hepatitis C virus, arthritides, and arthromyalgia. Elsevier Masson; 2003.

148. Gupta N. Rheumatologic Manifestations of Viral Hepatitis B and C. Journal of Hepatitis. 2015;1(1).

149. Nissen M, Fontanges E, Allam Y, Zoulim F, Trepo C, Miossec P. Rheumatological manifestations of hepatitis C: incidence in a rheumatology and non-rheumatology setting and the effect of methotrexate and interferon. Rheumatology. 2005;44(8):1016-20.

150. Food U, Administration D. FDA Drug Safety Communication: FDA warns that DPP-4 inhibitors for type 2 diabetes may cause severe joint pain. Drug safety and availability August. $2015 ; 28$.

151. Chaicha-Brom T, Yasmeen T. DPP-IV inhibitor-associated arthralgias. Endocr Pract. 2013;19(2):377.

152. Hart FD. Drug-Induced Arthritis and Arthralgia. Drugs. $1984 ; 28(4): 347-54$. 
153. Ozaras N, Rezvani A. Diffuse skeletal pain after administration of alendronate. Indian journal of pharmacology. 2010;42(4):245.

154. Campion J, Western A. Statins and joint pain. British journal of clinical pharmacology. 2008;66(4):570-1.

155. Beutler M, Hartmann K, Kuhn M, Gartmann J. Arthralgias and omeprazole. BMJ : British Medical Journal. 1994;309(6969):1620-

156. Jovanović M. Current concepts of pathophysiology, epidemiology and classification of pruritus. Srpski arhiv za celokupno lekarstvo. 2014;142(1-2):106-12.

157. Polat M, Öztas P, Ilhan MN, Yalçin B, Alli N. Generalized Pruritus. American journal of clinical dermatology. 2008;9(1):39-44.

158. ValsecchiR,CainelliT.Generalized pruritus: a manifestation of iron deficiency. Archives of dermatology. 1983;119(8):630-.

159. Tarikci N, Kocatürk E, Güngör Ş, Oğuz Topal I, Ülkümen Can P, Singer R. Pruritus in systemic diseases: a review of etiological factors and new treatment modalities. The Scientific World Journal. $2015 ; 2015$.

160. Deen K, O’Brien B, Wu J. Invisible Mycosis fungoides: Not to be missed in chronic pruritus. Dermatology and therapy. 2015;5(3):213-6.

161. Johansson P, editor Epidemiology of the myeloproliferative disorders polycythemia vera and essential thrombocythemia. Seminars in thrombosis and hemostasis; 2006: Copyright(C) 2006 by Thieme Medical Publishers, Inc., 333 Seventh Avenue, New York, NY 10001, USA.

162. Stein BL, Moliterno AR, Tiu RV. Polycythemia vera disease burden: contributing factors, impact on quality of life, and emerging treatment options. Annals of hematology. 2014;93(12):1965-76.

163. Misery L, Brenaut E, Le Garrec R, Abasq C, Genestet S, Marcorelles P, et al. Neuropathic pruritus. Nature reviews Neurology. 2014;10(7):408.

164. Oaklander AL. Neuropathic Itch. Seminars in cutaneous medicine and surgery. 2011;30(2):87-92.

165. Hollowell JG, Staehling NW, Flanders WD, Hannon WH, Gunter EW, Spencer CA, et al. Serum TSH, T4, and thyroid antibodies in the United States population (1988 to 1994): National Health and Nutrition Examination Survey (NHANES III). The Journal of Clinical Endocrinology \& Metabolism. 2002;87(2):489-99.

166. Artantaş Ş, Gül Ü, K1lıç A, Güler S. Skin findings in thyroid diseases. European journal of internal medicine. 2009;20(2):158-61.

167. Bergman H, Melamed N, Koren G. Pruritus in pregnancy: Treatment of dermatoses unique to pregnancy. Canadian Family Physician. 2013;59(12):1290-4.

168. Lammert F, Marschall H-U, Glantz A, Matern S. Intrahepatic cholestasis of pregnancy: molecular pathogenesis, diagnosis and management. Journal of hepatology. 2000;33(6):101221.

169. English N, Rao J. Case Report: Acute fatty liver of pregnancy with hypoglycaemia, diabetes insipidus and pancreatitis, preceded by intrahepatic cholestasis of pregnancy. BMJ case reports. $2015 ; 2015$.

170. Vanjak D, Moreau R, Roche-Sicot J, Soulier A, Sicot C. Intrahepatic cholestasis of pregnancy and acute fatty liver of pregnancy: An unusual but favorable association? Gastroenterology. 1991;100(4):1123-5.

171. Heitkemper T, Hofmann T, Phan NQ, Ständer S. Aquagenic pruritus: associated diseases and clinical pruritus characteristics.
JDDG: Journal der Deutschen Dermatologischen Gesellschaft. 2010;8(10):797-804.

172. Yosipovitch G. Chronic pruritus: a paraneoplastic sign. Dermatologic therapy. 2010;23(6):590-6.

173. Mealy MA, Wingerchuk DM, Greenberg BM, Levy M. Epidemiology of neuromyelitis optica in the United States: a multicenter analysis. Archives of neurology. 2012;69(9):1176-80.

174. Elsone L, Townsend T, Mutch K, Das K, Boggild M, Nurmikko T, et al. Neuropathic pruritus (itch) in neuromyelitis optica. Multiple Sclerosis Journal. 2013;19(4):475-9.

175. TARANU T, ESANU I, TOADER MP. Pruritus in the elderly. Pathophysiological, clinical, laboratory and therapeutic approach. The Medical-Surgical Journal. 2014;118(1):33-8.

176. Ward JR, Bernhard JD. Willan's itch and other causes of pruritus in the elderly. International journal of dermatology. 2005;44(4):267-73.

177. Parker S. The skin and HIV: no superficial matter. Topics in antiviral medicine. 2014;22(4):680-4.

178. Domínguez Moreno R, Morales Esponda M, Echazarreta R, Lorena N, Olan Triano R, Gutiérrez Morales JL. Esclerosis múltiple: revisión de la literatura médica. Revista de la Facultad de Medicina (México). 2012;55(5):26-35.

179. Vaa BE, Wolanskyj AP, Roeker L, Pardanani A, Lasho TL, Finke CM, et al. Pruritus in primary myelofibrosis: clinical and laboratory correlates. American journal of hematology. 2012;87(2):136-8

180. Chen J-P, Reich L, Chung H. Anxiety disorders. Western Journal of Medicine. 2002;176(4):249-53.

181. Mackenzie TB, Popkin MK. Organic anxiety syndrome. The American journal of psychiatry. 1983.

182. Welch LW, Bear D. Organic disorders of personality. New Directions for Student Leadership. 1990;1990(47):87-101.

183. Butler C, Zeman AZJ. Neurological syndromes which can be mistaken for psychiatric conditions. Journal of Neurology, Neurosurgery \&amp; Psychiatry. 2005;76(suppl 1):i31-i8.

184. White R, Pickering A, Spathis G. Mood disorder and chronic hypercalcemia. Journal of psychosomatic research. 1996;41(4):3437 .

185. Inzucchi SE. Understanding hypercalcemia. Postgraduate Medicine. 2015;115(4):69-76.

186. Coker LH, Rorie K, Cantley L, Kirkland K, Stump D, Burbank N, et al. Primary Hyperparathyroidism, Cognition, and Health-Related Quality of Life. Annals of Surgery. 2005;242(5):64250 .

187. Volpi-Abadie J, Kaye AM, Kaye AD. Serotonin Syndrome. The Ochsner Journal. 2013;13(4):533-40.

188. Frank C. Recognition and treatment of serotonin syndrome. Canadian Family Physician. 2008;54(7):988-92.

189. Lin L-R, Zhang H-L, Huang S-J, Zeng Y-L, Xi Y, Guo X-J, et al. Psychiatric manifestations as primary symptom of neurosyphilis among HIV-negative patients. The Journal of neuropsychiatry and clinical neurosciences. 2014;26(3):233-40.

190. Crozatti LL, de Brito MH, Lopes BNA, de Campos FPF. Atypical behavioral and psychiatric symptoms: Neurosyphilis should always be considered. Autopsy \& Case Reports. 2015;5(3):43-7.

191. Marra CM. Neurosyphilis. Continuum: Lifelong Learning in Neurology. 2015;21(6, Neuroinfectious Disease):1714-28. 
192. Krpan D, O'Connor A. The man who mistook his wife for a hat: Macat Library; 2017.

193. Taylor JB, Prager LM, Quijije NV, Schaefer PW. Case 21-2018: A 61-Year-Old Man with Grandiosity, Impulsivity, and Decreased Sleep. New England Journal of Medicine. 2018;379(2):1829.

194. Hackett ML, Yapa C, Parag V, Anderson CS. Frequency of depression after stroke: a systematic review of observational studies. Stroke. 2005;36(6):1330-40.

195. Hackett ML, Köhler S, T O'Brien J, Mead GE. Neuropsychiatric outcomes of stroke. The Lancet Neurology. 2014;13(5):525-34.

196. Smith FA, Huffman JC, Stern TA. Patients With Cerebrovascular Disease and Traumatic Brain Injury Massachusetts General Hospital Handbook of General Hospital Psychiatry. Seventh ed2018.

197. Mercy L, Hodges JR, Dawson K, Barker RA, Brayne C. Incidence of early-onset dementias in Cambridgeshire, United Kingdom. Neurology. 2008;71(19):1496-9.

198. Rosso SM, Donker Kaat L, Baks T, Joosse M, de Koning I, Pijnenburg Y, et al. Frontotemporal dementia in The Netherlands: patient characteristics and prevalence estimates from a populationbased study. Brain. 2003;126(Pt 9):2016-22.

199. Bang J, Spina S, Miller BL. Frontotemporal dementia. The Lancet. 2015;386(10004):1672-82.

200. Johnson JK, Diehl J, Mendez MF, Neuhaus J, Shapira JS, Forman M, et al. Frontotemporal lobar degeneration: demographic characteristics of 353 patients. Arch Neurol. 2005;62(6):925-30.

201. Alagiakrishnan K, Wiens C. An approach to drug induced delirium in the elderly. Postgraduate Medical Journal. 2004;80(945):388-93

202. Francis J, Young GB. Diagnosis of delirium and confusional states: Uptodate; 2014 [Available from: https://www.uptodate.com/ contents/diagnosis-of-delirium-and-confusional-states.

203. Dalmau J, Graus F. Antibody-Mediated Encephalitis. New England Journal of Medicine. 2018;378(9):840-51.

204. Dalmau J, Graus F. Antibody-Mediated Encephalitis. The New England journal of medicine. 2018;378(9):840-51.

205. Alamowitch S, Graus F, Uchuya M, Reñe’ R, Bescansa E, Delattre JY. Limbic encephalitis and small cell lung cancer. Clinical and immunological features. Brain. 1997;120:923-8.

206. Guasp M, Arino H, Dalmau J. [Autoimmune encephalitis]. Revista de neurologia. 2018;66(s02):S1-s6.

207. Pirritano D, Plastino M, Bosco D, Gallelli L, Siniscalchi A, De Sarro G. Gambling disorder during dopamine replacement treatment in Parkinson's disease: a comprehensive review. BioMed research international. 2014;2014:728038.

208. Bostwick JM, Hecksel KA, Stevens SR, Bower JH, Ahlskog $\mathrm{JE}$, editors. Frequency of new-onset pathologic compulsive gambling or hypersexuality after drug treatment of idiopathic Parkinson disease. Mayo Clinic Proceedings; 2009: Elsevier.

209. Heiden P, Heinz A, Romanczuk-Seiferth N. Pathological gambling in Parkinson's disease: what are the risk factors and what is the role of impulsivity? The European journal of neuroscience. 2017:45(1):67-72.

210. Blair RD. Temporal lobe epilepsy semiology. Epilepsy research and treatment. 2012;2012.

211. Sanchez-Gistau V, Sugranyes G, Bailles E, Carreno M,
Donaire A, Bargallo N, et al. Is major depressive disorder specifically associated with mesial temporal sclerosis? Epilepsia. 2012;53(2):38692.

212. Mark Sadler R. The syndrome of mesial temporal lobe epilepsy with hippocampal sclerosis: clinical features and differential diagnosis 2006. 27-37 p.

213. Ministerio de Salud, Instituto nacional de salud. Informe quincenal epidemiológico nacional. 2013.

214. Bluhm RE, Bobbitt RG, Welch LW, Wood AJ, Bonfiglio JF, Sarzen C, et al. Elemental mercury vapour toxicity, treatment, and prog nosis after acute, intensive exposure in chloralkali plant workers. Part I: History, neuropsychological findings and chelator effects. Human $\& \quad$ experimental toxicology. 1992;11(3):201-10.

215. Tsirlin A, Oo Y, Sharma R, Kansara A, Gliwa A, Banerji M. Pheochromocytoma: a review. Maturitas. 2014;77(3):229-38.

216. Kantorovich V,Eisenhofer G,Pacak K.Pheochromocytoma. Annals of the New York Academy of Sciences. 2008;1148(1):462-8.

217. Zardawi IM. Phaeochromocytoma masquerading as anxiety and depression. The American journal of case reports. 2013;14:161.

218. Smith JP, Randall CL. Anxiety and Alcohol Use Disorders: Comorbidity and Treatment Considerations. Alcohol Research : Current Reviews. 2012;34(4):414-31

219. McIntosh C, Chick J. Alcohol and the nervous system. Journal of Neurology, Neurosurgery \&amp;amp; Psychiatry. 2004;75(suppl 3):iii16.

220. Heffernan TM. The impact of excessive alcohol use on prospective memory: a brief review. Current Drug Abuse Reviews. 2008;1(1):36-41.

221. Bernardin F, Maheut-Bosser A, Paille F. Cognitive Impairments in Alcohol-Dependent Subjects. Frontiers in Psychiatry. 2014;5:78.

222. Millward L, Kelly P, King A, Peters T. Anxiety and depression in the acute porphyrias. Journal of inherited metabolic disease. 2005;28(6):1099-107. 